\title{
Surgery of pancreas tumors in pediatric and adolescent patients: a single institution experience in South America
}

OSCAR RICARDO PAREDES TORRES ( $\sim$ oscarp40@hotmail.com )

Instituto Nacional de Enfermedades Neoplásicas: Instituto Nacional de Enfermedades Neoplasicas https://orcid.org/0000-0002-7681-2369

\section{Yoshikuni Kawaguchi}

University of Tokyo Hospital: Tokyo Daigaku Igakubu Fuzoku Byoin

\section{Eloy Ruiz Figueroa}

Instituto Nacional de Enfermedades Neoplásicas: Instituto Nacional de Enfermedades Neoplasicas

\section{Eduardo Payet Meza}

Instituto Nacional de Enfermedades Neoplásicas: Instituto Nacional de Enfermedades Neoplasicas

\section{Francisco Berrospi Espinoza}

Instituto Nacional de Enfermedades Neoplásicas: Instituto Nacional de Enfermedades Neoplasicas

\section{Original Article}

Keywords: Pancreas tumor, children, adolescents, surgery

Posted Date: February 5th, 2021

DOl: https://doi.org/10.21203/rs.3.rs-170614/v1

License: (c) (1) This work is licensed under a Creative Commons Attribution 4.0 International License. Read Full License

Version of Record: A version of this preprint was published at Pediatric Surgery International on March 19th, 2021. See the published version at https://doi.org/10.1007/s00383-021-04877-3. 


\section{Abstract \\ Purpose}

Pancreas tumors are extremely rare in pediatric and adolescent patients. Surgical resection is the mainstay of treatment; however, the data is limited with respect to morbidity and mortality. We aimed to evaluate short- and long-term outcomes of pediatric and adolescent patients who underwent surgical resection of pancreatic tumors.

\section{Methods}

Patients $\leq 18$ years old who underwent resection of pancreas tumor at the National Institute of Neoplastic Diseases INEN during 2000-2020 were included.

\section{Results}

Thirty-four patients were diagnosed; 28 patients were female and 6 were male. The median age was 13.4 years old. Histological diagnosis was solid pseudopapillary neoplasm (SPN) ( $n=29,85.3 \%)$, pancreatoblastoma $(n=3)$, neuroendocrine carcinoma $(n=1)$, and insulinoma $(n=1)$. No patient experienced postoperative mortality and $15(44.1 \%)$ patients developed postoperative complications including pancreatic fistula as the most frequent. Under a median follow-up period of $33.8(0.5-138)$ months, $4(11.8 \%)$ patients died. Of the 29 patients with SPN, the 3 -and-5-year OS was $100 \%$ and $83.1 \%$, respectively.

\section{Conclusions}

SPN was the most frequent cause of surgical treatment for pediatric and adolescent patients in the highvolume cancer center in Peru and was associated with favorable survival. Pancreaticoduodenectomy was safely performed in this patient group with acceptable morbidity and zero mortality.

\section{Introduction}

Pancreas tumors are extremely rare in pediatric and adolescent patients. Solid pseudopapillary neoplasm (SPN) and pancreatoblastoma are relatively common in this patient group [1, 2]. SPN was the most frequent pancreas tumor in patients with 10-20 years old, and pancreatoblastoma was generally found in patients $<10$ years old $[3,4]$. Other histological types including neuroendocrine tumors (NET), acinar carcinoma, ductal carcinoma, neuroblastoma, lymphoma were reported in pediatric and adolescent patients [2,5-7]. Surgical resection is the mainstay of treatment and provides a better survival and lower recurrence rate [5]. Generally, radiotherapy and chemotherapy were used as adjuvant treatments. 
adolescent patients who underwent pancreatectomy [8]. The aim of this study is to evaluate clinical and pathological characteristics, short-term (morbidity and mortality) and long-term outcomes (overall and disease-free survival) in pediatric and adolescent patients who underwent pancreas resection for benign and malignant pancreas tumors.

\section{Materials And Methods}

\section{Study population}

Patients who underwent resection of pancreas benign and malignant primary tumors with curative intent at the National Institute of Neoplastic Diseases INEN from January 2000 through January 2020 were identified from a prospectively compiled database. Patients who underwent surgery at the age $\leq$ 18 years old (i.e., pediatric and adolescent patients) were included in the study. Demographic characteristics and short- and long-term outcomes were evaluated. Pancreas tumors were diagnosed based on the current WHO classification[9]. The study was approved by the institutional review board at the National Institute of Neoplastic Diseases INEN.

\section{Preoperative evaluation}

All patients underwent computed tomography of the thorax, abdomen, and pelvis. A preoperative tumor biopsy was not routinely performed. Blood test including a complete blood count, hepatic, renal function, and a coagulation profile was performed. A cardiological, psychological, and nutritional evaluation was performed routinely before surgery. No patients received neoadjuvant chemotherapy and radiotherapy.

\section{Surgical technique}

The surgical procedure was performed based upon the tumor location and involvement of adjacent organs. For tumors located at the pancreas head, pancreaticoduodenectomy (PD) was performed using the conventional or pylorus preserving method. D2 lymph node dissection was generally performed. For patients with pancreatic tumors invaded to the portal vein and/or superior mesenteric vein, combined resection of the vessels and reconstruction were performed. The anastomosis of pancreas stump was performed depending on pancreas texture and main pancreatic duct diameter. In this series, we used duct to mucosa or modified telescopic anastomosis $[10,11]$. For tumors located at the pancreas tail, distal pancreatectomy was performed, with or without splenectomy. For spleen-preserving distal pancreatectomy, Warshaw or Kimura technique was used depending on the surgeon's preferences [12, 13]. Central pancreatectomy was performed for tumors located at the neck and proximal body of the pancreas and the distal pancreatic stump was anastomosed using a Roux-en-Y jejunal loop or a pancreatic-gastric anastomosis [14]. For small tumors which are located away from the main pancreatic duct, enucleation was selected [15].

\section{Postoperative management}


An enteral feeding tube was routinely used in patients who underwent PD and central pancreatectomy. In patients who underwent distal pancreatectomy, an enteral feeding tube was only used in case of malnutrition and albumin $<35 \mathrm{~g} / \mathrm{dL}$. At the postoperative day (POD) 1 or 2 enteral nutrition was started through an enteral feeding tube, oral intake was started at POD 3 in patients who underwent an enteral anastomosis. Amylase levels in blood and fluid from abdominal drains were measured at POD 1, 3, 5, and 7. The discharge amount from abdominal drains was measured. When patients had pancreatic fistula, somatostatin analog was used [16]. Abdominal drains were removed when amylase level was $<5000 \mathrm{U} / \mathrm{L}$; after POD 5 or on the day of patient discharge. Postoperative morbidity and mortality were defined as complications and mortality which occurred within 30 days after surgery. All complications were categorized according to the Clavien-Dindo classification [17].

\section{Variable studied}

Demographic characteristics (age, symptoms, tumor location, tumor size, and histology), surgical and pathological outcomes (surgical procedure, type of anastomosis, and nodal status), postoperative outcomes (hospital stay and postoperative complications), and long-term outcomes were evaluated. Tumors were classified according to the current WHO classification for pancreatic tumors [9].

\section{Statistical analysis}

Categorical variables are expressed as number (\%) and continuous variables are expressed as median (ranges). Overall survival (OS) and recurrence-free survival (RFS) curves were constructed using the Kaplan-Meier method. Deaths without recurrence were censored for the RFS analysis. A p-value $<0.05$ was considered statistically significant. Statistical analysis was conducted using SPSS 22.

\section{Results}

\section{Study population}

From 2000 to 2020, 34 patients underwent pancreas resection. The annual proportion of pancreatic malignancy in pediatric and adolescent patients at our institution is approximately $0.3 \%$ (1-2 pancreatic malignancy of 650 pediatric and adolescent patients with malignancy. Demographic and clinicopathologic characteristics were shown in Table 1. The median (range) age was 13.4 (3-18) years, and $28(82.4 \%)$ patients were female and $6(17.6 \%)$ were male. Symptoms were abdominal pain in 25 (73.5\%) patients, palpation of intraabdominal mass in $3(8.8 \%)$ patients, Cushing syndrome in $1(2.9 \%)$ patient, and no symptoms in $5(14.7 \%)$ patients.

\section{Surgical and histopathologic outcomes}

Table 2 shows surgical and histopathologic outcomes. Of the 34 patients, $19(55.9 \%)$ underwent pancreaticoduodenectomy, $10(29.4 \%)$ underwent distal pancreatectomy, 4 (11.8\%) underwent central pancreatectomy, and $1(2.9 \%)$ underwent enucleation. Pancreatic-jejunal anastomosis was performed in $22(64.6 \%)$ patients. and pancreatic-aastric anastomosis was performed in $1(2.9 \%)$ patient who Loading [MathJax]/jax/output/CommonHTML/jax.js 
underwent central pancreatectomy. Median (range) operative time was 343 (125-570) minutes and the median (range) estimated blood loss was $440(20-3000) \mathrm{mL}$. Diagnoses of disease were SPN $(\mathrm{n}=29$, $85.3 \%)$, pancreatoblastoma $(n=3,8.8 \%)$, neuroendocrine carcinoma $(n=1,2.9 \%)$, and insulinoma $(n=1$, $2.9 \%$ ). Median (range) tumor diameter was $7.5(2.0-13.5) \mathrm{cm}$. Lymph node metastasis was found in 2 (5.9\%) patients who had a diagnosis of SPN. One patient underwent pylorus-preserving pancreaticoduodenectomy with vascular reconstruction because the superior mesenteric vein was involved by the tumor; the final pathology showed no vascular infiltration of the tumor.

\section{Postoperative outcomes}

Postoperative outcomes were shown in Table 3. No patient experienced postoperative mortality and 15 (44.1\%) patients developed postoperative complications including pancreatic fistula $(n=7,20.5 \%)$, pancreatitis $(n=2,5.9 \%)$, intra-abdominal fluid collection $(n=2,5.9 \%)$, postoperative hemorrhage $(n=2$, $5.9 \%)$, delayed gastric emptying $(n=1,2.9 \%)$ and intestinal obstruction $(n=1,2.9 \%)$. Reoperation was performed in $2(6.3 \%)$ patients undergoing pylorus-preserving pancreaticoduodenectomy because of intestinal obstruction in $1(2.9 \%)$ patient and postoperative hemorrhage in $1(2.9 \%)$ patient. The median (range) length of hospital stay was $12(4-28)$ days. The postoperative complications by the type of procedures were summarized in Supplementary Table 1.

\section{OS and RFS}

Under a median follow-up period of $33.8(0.5-138)$ months, $4(11.8 \%)$ patients died. Of the 29 patients with SPN, 2 patients died; one patient because of liver cirrhosis and other patients because of liver metastasis. Of the 3 patients with pancreatoblastoma, 1 patient died because of liver metastasis. Of the 2 patients with NET/NEC, 1 patient died because of liver and lung metastases. Demographics and clinicopathologic factors only in patients with SPN were shown in Supplementary Table 2. Figure 1 shows OS and RFS curves in patients with SPN. The 3-and-5-year OS was $100 \%$ and $83.1 \%$, respectively. The 3-and-5-year RFS was 100\% and 93.3\%, respectively.

\section{Discussion}

Primary pancreatic tumors are rare in pediatric and adolescent patients. Our study showed outcomes of the largest series in South America and the second largest single institution series worldwide. A total of 34 patients underwent resection without mortality.

In line with previous studies $[1,2,5,8,18]$, the proportion of female sex was higher (82.4\%) and the most common histology type was SPN in this population. Most of the patients were $\geq 10$ years old $(88.2 \%)$. The most frequent symptom was abdominal pain. These were also in line with previous studies, showing that the demographic characteristics of pediatric and adolescent pancreatic tumors may be common regardless of the regions worldwide $[1,2,19,20]$.

SPN is a low grade malignant pancreas tumors which contain solid and cystic components and mainly 
SPN was 1: 9.5. The size of SPN is generally smaller in male patients than in female patients, and SPN diagnosed in male patients mainly contains solid components [19]. In pediatric and adolescent patients, SPN is generally found at the age from 10 to 20 years old [4]. Our study showed that the 3-and 5-year OS rates were $100 \%$ and $83.1 \%$ in pediatric and adolescent patients with SPN, respectively. This is in line with previous studies which showed that the OS in pediatric and adolescent patients with SPN was more than $95 \%$ and was better than OS in this patient group with other histology types of pancreas tumors $[1,5,8$, $20,21]$.

Pancreatoblastoma is the second most common histology type in our study. Pancreatoblastoma was originally termed as infantile pancreatic carcinoma by Becker in 1957 [22] and is an extremely rare pancreas neoplasm which contains typical squamous corpuscles and tumor cells with acinar, glandular, or undifferentiated appearance [23]. It is predominant in male patients who are from 0 to 20 years old and has an association with Beckwith-Wiedemann syndrome [3, 24]. Serum alpha-fetoprotein level is elevated in most patients. Mylonas, et al reported 21 pediatric and adolescent patients with pancreatoblastoma. The median age of the patients 5.5 years old at the time of diagnosis [20]. In our study, of the three patients, two are alive with no evidence of recurrence after surgery and one died because of hepatic recurrence at 46 months after surgery. Bien, et al reported 20 pediatric and adolescent patients with pancreatoblastoma in a multicenter study [25]. The 5-year OS was $79.4 \%$ and the 5 -year event-free survival was $58.8 \%$. Complete surgical resection was a prognostic factor for a better event-free survival in univariate analysis.

The largest single institution retrospective study about this topic was reported in Asia [2]. The study included 104 pediatric and adolescent patients between 2007 and 2018. Other studies included approximately 30 patients mainly from North America. Our study is the largest series in the population of South America and found that female sex is dominant and SPN was the most common histology types in line with previous studies in other regions. Mylonas et al [20], reported a retrospective multicenter study using Surveillance, Epidemiology and, End Results (SEER) database, and included 114 pediatric and adolescent patients from 1973-2013. In this study, the most common histology type was NET with 40 (35\%) patients followed by epithelial tumors with $29(25 \%)$. A total of $73(64 \%)$ patients had surgical treatment. Another study using the SEER database from 1973-2004, showing that the incidence of pancreas tumors in pediatric and adolescent patients was 0.018 per 100000 people [5].

Pancreaticoduodenectomy was the most frequent surgical procedure in our study which accounts for 19 patients (55.9\%). Pancreaticoduodenectomy in pediatric and adolescent patients had been reported but the number of cases was low [26]. In children, pylorus-preserving pancreaticoduodenectomy may be considered to preserve gastric function $[27,28]$. Mansfield et al reported that morbidity rate after pancreaticoduodenectomy was lower in patients $\leq 30$ years old than in adult patients [29]. In our study, no patient experienced postoperative mortality and 15 patients (44.1\%) developed postoperative complications including 5 patients $(14.7 \%)$ who had major complications. Pancreatic fistula was found in $6(31.5 \%)$ patients undergoing pancreaticoduodenectomy versus $1(10 \%)$ patient undergoing distal 
Our study is a retrospective study with a small number of patients. Nonetheless, given the rarity of pancreas tumors in pediatric and adolescent patients, our study is the second largest series worldwide and showed outcomes of pancreas tumors for this patient group in South America. Another limitation is that the functional change after pancreatectomy was not followed because most patients lived in remote areas far from our institution.

In conclusion, SPN was the most frequent cause of surgical treatment for pediatric and adolescent patients in the high-volume cancer center in Peru and was associated with favorable survival.

Pancreaticoduodenectomy was safely performed in this patient group with acceptable morbidity and zero mortality.

\section{Declarations}

\section{Compliance with Ethical Standards}

\section{Conflicts of interest:}

The authors declare that they have no conflicts of interest.

\section{Ethics approval:}

Ethical approval was waived by the local Ethics Committee of National Institute of Neoplastic Diseases in view of the retrospective nature of the study and all the procedures being performed were part of the routine care.

\section{Funding:}

The authors did not receive support from any organization for the submitted work.

\section{Author contributions:}

All authors contributed to the study conception and design. Conceptualization: Francisco Berrospi Espinoza; Methodology: Eduardo Payet Meza; Formal analysis and investigation: Eloy Ruiz Figueroa; Writing - original draft preparation: Oscar Paredes Torres; Writing - review and editing: Yoshikuni Kawaguchi; Supervision: Francisco Berrospi Espinoza. II authors read and approved the final manuscript.

\section{References}

1. Rojas Y, Warneke CL, Dhamne CA, Tsao K, Nuchtern JG, Lally KP et al. Primary malignant pancreatic nennlasm in children and adnlescents; A 20 year experience. J Pediatr Surg [Internet]. 
2012;47:2199-204. Available from: http://dx.doi.org/10.1016/j.jpedsurg.2012.09.005

2. Cheng $H$, Yang S, Ren Q, Yang W, Han W, Chang X et al. Pancreatectomies for Pediatric Pancreatic Tumors: A Single Institute Experience from 2007 to 2018. J Pediatr Surg [Internet]. 2019;5-9. Available from: https://doi.org/10.1016/j.jpedsurg.2019.08.051

3. Nasher O, Hall NJ, Sebire NJ, Coppi P, De, Pierro A. Pancreatic tumours in children: diagnosis, treatment and outcome. Pediatr Surg Int [Internet]. 2015;31:831-5. Available from: https://doi.org/10.1007/s00383-015-3727-7

4. Speer AL, Barthel ER, Patel MM, Grikscheit TC. Solid pseudopapillary tumor of the pancreas: a singleinstitution 20-year series of pediatric patients. J Pediatr Surg [Internet]. 2012;47:1217-22. Available from: http://dx.doi.org/10.1016/j.jpedsurg.2012.03.026

5. Perez EA, Gutierrez JC, Koniaris LG, Neville HL, Thompson WR, Sola JE. Malignant pancreatic tumors: incidence and outcome in 58 pediatric patients. J Pediatr Surg [Internet]. 2009;44(1):197-203. Available from: http://dx.doi.org/10.1016/j.jpedsurg.2008.10.039

6. Park M, Koh KN, Kim BE, Im HJ, Kim DY, Seo JJ. Pancreatic neoplasms in childhood and adolescence. J Pediatr Hematol Oncol [Internet]. 2011;33:295-300. Available from: doi: 10.1097/MPH.0b013e318206990a

7. Marchegiani G, Crippa S, Malleo G, Partelli S, Capelli P, Pederzoli P et al. Surgical treatment of pancreatic tumors in childhood and adolescence: Uncommon neoplasms with favorable outcome. Pancreatology [Internet]. 2011;11(4):383-9. Available from: http://dx.doi.org/10.1159/000330212

8. Scandavini C, Valente R, Rangelova E, Segersv R, Stenman J, Arnelo U et al. Pancreatectomies for pancreatic neoplasms in pediatric and adolescent age: A single institution experience. Pancreatology [Internet]. 2017;10-3. Available from: https://doi.org/10.1016/j.pan.2017.12.009

9. International Agency for Research on Cancer. Digestive system tumours. 5th ed. WHO Classification of Tumours Editorial, Board, editors. Lyon (2019) 295-372 p

10. Celis J, Berrospi F, Ruiz E, Payet E. Técnica modificada de la anastomosis pancreatoyeyunal en la pancreatoduodenectomía proximal. Rev Gastroenterol del Peru. 2000;20(11)

11. Celis J, Berrospi F, Ruiz E, Payet E, Chavez I, Young F (2006) Reconstruccion despues de pancreatoduodenectomia proximal mediante anastomosis pancreatoyeyunal simplifi cada. Resultados operatorios en 198 pacientes. Rev Gastroenterol del Perú 26(3):271-277

12. Ferrone CR, Konstantinidis IT, Sahani DV, Wargo JA, Fernandez-Del Castillo C, Warshaw AL (2011) Twenty-three years of the Warshaw operation for distal pancreatectomy with preservation of the spleen. Ann Surg 253(6):1136-1139

13. Kimura W, Yano M, Sugawara S, Okazaki S, Sato T, Moriya T et al (2007) Spleen-preserving distal pancreatectomy with conservation of the splenic artery and vein. J Hepatobiliary Pancreat Sci 17(6):813-823

14. Christein John; Smoot Roly; Farnell Michael. Central pancreatectomy A technique for the Resection of Pancreatic Neck lesions. J Transl Med Res. 2006;141 
15. Antonakis PT, Ashrafian H, Martinez-Isla A (2015) Pancreatic insulinomas: Laparoscopic management. World J Gastrointest Endosc 7(16):1197

16. Bassi C, Marchegiani G, Dervenis C, Sarr M. Pancreas The 2016 update of the International Study Group (ISGPS) definition and grading of postoperative pancreatic fistula: 11 Years After. Surgery [Internet]. 2016;161(3):584-91. Available from: http://dx.doi.org/10.1016/j.surg.2016.11.014

17. Dindo D, Demartines N, Clavien P-A. Classification of Surgical Complications. Ann Surg [Internet]. 2004 Aug [cited 2020 Apr 5];240(2):205-13. Available from: http://journals.Iww.com/00000658200408000-00003

18. Akker M, Van Den, Angelini P, Taylor G, Chami R, Gerstle JT, Gupta A. Malignant pancreatic tumors in children: a single-institution series $\otimes$. J Pediatr Surg [Internet]. 2012;47(4):681-7. Available from: http://dx.doi.org/10.1016/j.jpedsurg.2011.11.046

19. Park DJ, Lee H, Kim H, Yang H, Lee KU, Choe KJ. Predictors of operative morbidity and mortality in gastric cancer surgery. Br J Surg. 2005;1099-102

20. Sacco MG, Colin C, Seth DG, Abdullah F, Meoded A, Lukish JR et al. Pancreatic surgery for tumors in children and adolescents. Pediatr Surg Int. 2016

21. Dai G, Huang L, Du Y, Yang L, Yu P (2015) Solid pseudopapillary neoplasms of the pancreas: Clinical analysis of 45 cases. Int J Clin Exp Pathol 119(9):83-89

22. Mylonas KS, Nasioudis D, Tsilimigras DI, Doulamis IP, Masiakos PT, Kelleher CM. A population-based analysis of a rare oncologic entity: Malignant pancreatic tumors in children. J Pediatr Surg [Internet]. 2018;53(4):647-52. Available from: https://doi.org/10.1016/j.jpedsurg.2017.06.024

23. Choi SH, Kim SM, Oh JT, Park JY, Seo JM, Lee SK (2006) Solid pseudopapillary tumor of the pancreas: a multicenter study of 23 pediatric cases. J Pediatr Surg 41(12):1992-1995

24. BECKER WF. Pancreatoduodenectomy for carcinoma of the pancreas in an infant: Report of a case. Ann Surg. 1957;145(6)

25. Huang YJ, Yang W, Hu JJ, Zhu ZY, Qin H, Han W et al. Diagnosis and treatment of pancreatoblastoma in children: a retrospective study in a single pediatric center. Pediatr Surg Int [Internet]. 2019;35(11):1231-8. Available from: https://doi.org/10.1007/s00383-019-04524-y

26. Igna PD, Cecchetto G, Bisogno G, Conte M, Chiesa PL, Angelo PD et al. Pancreatic Tumors in Children and Adolescents: The Italian TREP Project Experience. 2010;(December 2009):675-80

27. Bien E, Godzinski J, Dall'Igna P, Defachelles AS, Stachowicz-Stencel T, Orbach D et al. Pancreatoblastoma: A report from the European cooperative study group for paediatric rare tumours (EXPeRT). Eur J Cancer [Internet]. 2011;47(15):2347-52. Available from: http://dx.doi.org/10.1016/j.ejca.2011.05.022

28. Picado O, Ferrantella A, Zabalo C, Rao K, Thorson CM, Sola JE et al. Treatment patterns and outcomes for pancreatic tumors in children: an analysis of the National Cancer Database. Pediatr Surg Int [Internet]. 2020;36(3):357-63. Available from: https://doi.org/10.1007/s00383-020-04617-z 29. Giuseppe D, Laura DP, Grimaldi C, Bertocchini A, Lo C, Monti L et al. Pancreaticoduodenectomy for Loading [MathJax]/jax/output/CommonHTML/jax.js , [Internet]. 2014;49(4):534-8. Available from: 
http://dx.doi.org/10.1016/j.jpedsurg.2013.09.010

30. Gillentine MA, Berry LN, Goin-Kochel RP, Ali MA, Ge J, Guffey D, Rosenfeld JA, Hannig V, Bader P, Proud M, Shinawi M, Graham BH 1, Lin A, Lalani SR, Reynolds J, Chen M, Grebe T, Minard CG, Stankiewicz P (2017) AL Beaudet and C, Schaaf. Pancreaticoduodenectomy for Pediatric and Adolescent Pancreatic Malignancy: A Single-Center Retrospective Analysis. J Pediatr Surg 47(3):549-562

31. Mansfield SA, Mahida JB, Dillhoff M, Porter K, Conwell D, Ranalli M et al. Pancreaticoduodenectomy outcomes in the pediatric, adolescent, and young adult population. J Surg Res [Internet]. 2016;204(1):232-6. Available from: http://dx.doi.org/10.1016/j.jss.2016.04.049

\section{Tables}

Due to technical limitations, the tables are only available as a download in the supplemental files section.

\section{Figures}

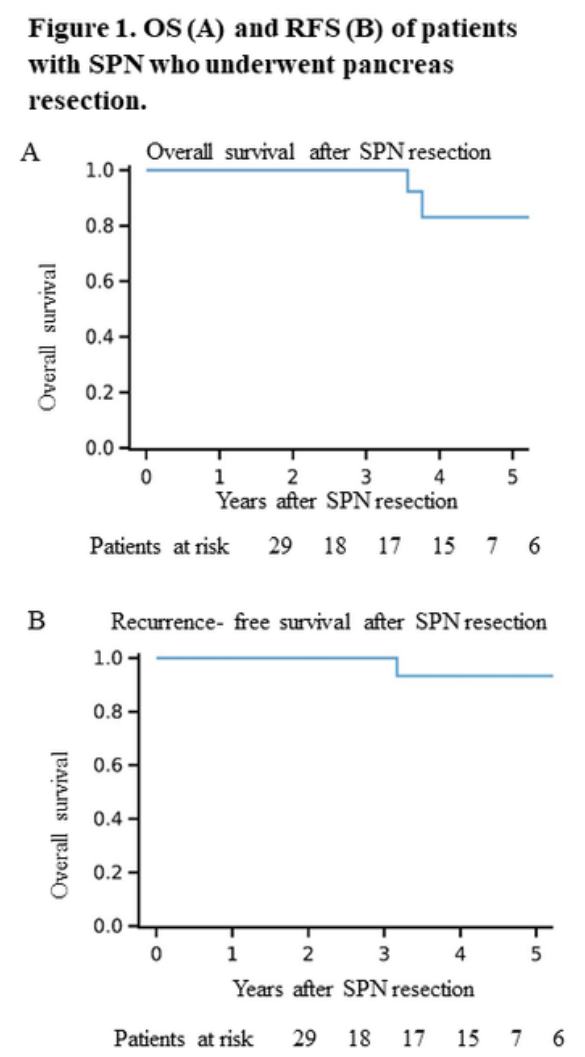

Figure 1

OS (A) and RFS (B) of patients with SPN who underwent pancreas resection.

\section{Supplementarv Files}


This is a list of supplementary files associated with this preprint. Click to download.

- SUPPLEMENTARYTABLE1PSI.xlsx

- SUPPLEMENTARYTABLE2PSI.xIsX

- TABLE1PSI.xIsx

- TABLE2PSI.xlsx

- TABLE3PSI.xIsX

- TABLE4PSI.xlsx 